\title{
Cryo-transmittance and -reflectance of filters and beamsplitters for the SIRTF Infrared Array Camera
}

\author{
Kenneth P. Stewart ${ }^{a}$, Manuel A. Quijada ${ }^{b}$ \\ ${ }^{a}$ Goddard Space Flight Center, Code 551, Greenbelt, MD 20771 \\ ${ }^{\mathrm{b}}$ Genesis Engineering Company, LLC, Lanham, MD 20706
}

\begin{abstract}
The Space Infrared Telescope Facility (SIRTF) Infrared Array Camera (IRAC) uses two dichroic beamsplitters, four bandpass filters, and four detector arrays to acquire images in four channels at wavelengths between 3 and $10 \mu \mathrm{m}$. Accurate knowledge of the pass bands is necessary because, in order to meet the science objectives, IRAC is required to do $2 \%$ relative photometry in each band relative to the other bands. We report the in-band and out-of-band polarized transmittance and reflectance of these optical elements measured near the instrument operating temperature of $1.4 \mathrm{~K}$. Details of the experimental apparatus, which include a continuous flow liquid helium optical cryostat and a Fourier transform infrared (FTIR) spectrometer are discussed.
\end{abstract}

Keywords: Cryogenic, infrared, space flight optics, transmittance, reflectance

\section{INTRODUUCTION}

The Space Infrared Telescope Facility contains three focal plane instruments, one of which is the Infrared Array Camera'. IRAC is a four channel camera that provides simultaneous images at $3.6,4.5,5.8$, and $8 \mu \mathrm{m}$. Each detector array has 256 by 256 pixels with a pixel field of view of 1.2 arcseconds, so that each image covers a total of 5.12 by 5.12 arcmin field of view. Two adjacent fields of view in the SIRTF focal plane are viewed by the four channels in pairs (3.6 and $5.8 \mu \mathrm{m} ; 4.5$ and 8.0 $\mu \mathrm{m})$. The 3.6 and $5.8 \mu \mathrm{m}$ arrays share the same entrance aperture in the focal plane; light is split by a dichroic beamsplitter so that these two arrays image the exact same piece of sky. Similarly, the 4.5 and $8.0 \mu \mathrm{m}$ arrays share an entrance aperture and image the same piece of sky. The two short wavelength channels use InSb and the two longer wavelength channels use Si:As IBC detectors. The IRAC point-source sensitivity requirements (5 sigma, $200 \mathrm{sec}$ ) at $3.6,4.5,5.8$, and $8.0 \mu \mathrm{m}$ are $6,7,36$, and $54 \mu \mathrm{Jy}$, respectively.

The IRAC instrument will address the four major scientific objectives defining the SIRTF mission. These objectives are (1) to study the early universe, (2) to search for and study brown dwarfs and superplanets, (3) to study ultraluminous galaxies and active galactic nuclei, and (4) to discover and study protoplanetary and planetary debris disks. In addition, IRAC is a general-purpose camera that will be used by observers on SIRTF for a wide variety of astronomical research programs.

\subsection{IRAC Optical Design}

IRAC views simultaneously two nearly adjacent $5.12 \times 5.12$ arcmin fields of view near the center of the SIRTF focal plane. A pickoff mirror reflects the light into the camera housing. Each of these fields is split into two channels by a dichroic beamsplitter, with the 3.6 and $5.8 \mu \mathrm{m}$ channels in one field of view and the 4.5 and $8.0 \mu \mathrm{m}$ channels in the other. The optical layout for two of the channels is shown in Figure 1. Each field of view has a lens doublet that reimages the SIRTF focal plane (located near the pickoff mirror) onto the detector arrays at a scale of $1.2 \mathrm{arcsec} / \mathrm{pixel}$ in each band. For Channels 1 and 3 the lens materials are $\mathrm{MgF}_{2}$ and $\mathrm{ZnS}$. For Channels 2 and 4 the lenses are $\mathrm{ZnSe}$ and $\mathrm{BaF}_{2}$. The beamsplitters reflect the short wavelength and transmit the long wavelength bands, and a Lyot stop is placed at the pupil to eliminate stray light. The fixed filter in front of each detector defines the bandpass. The image quality in the current optical design meets the wavefront error goal of $<0.05$ waves rms over each field of view and in all wavelengths in the bandpasses in all channels. The filter bandpasses were optimized to carry out the mission science objectives described above, as well as to provide maximum sensitivity in each band. In particular, comparing the flux detected in the 3.6 and $4.5 \mu \mathrm{m}$ bands will be a good discriminator 
in searches for brown dwarfs, and the 5.8 and $8.0 \mu \mathrm{m}$ bands were optimized to achieve the highest sensitivity for deep galaxy surveys ${ }^{2}$.

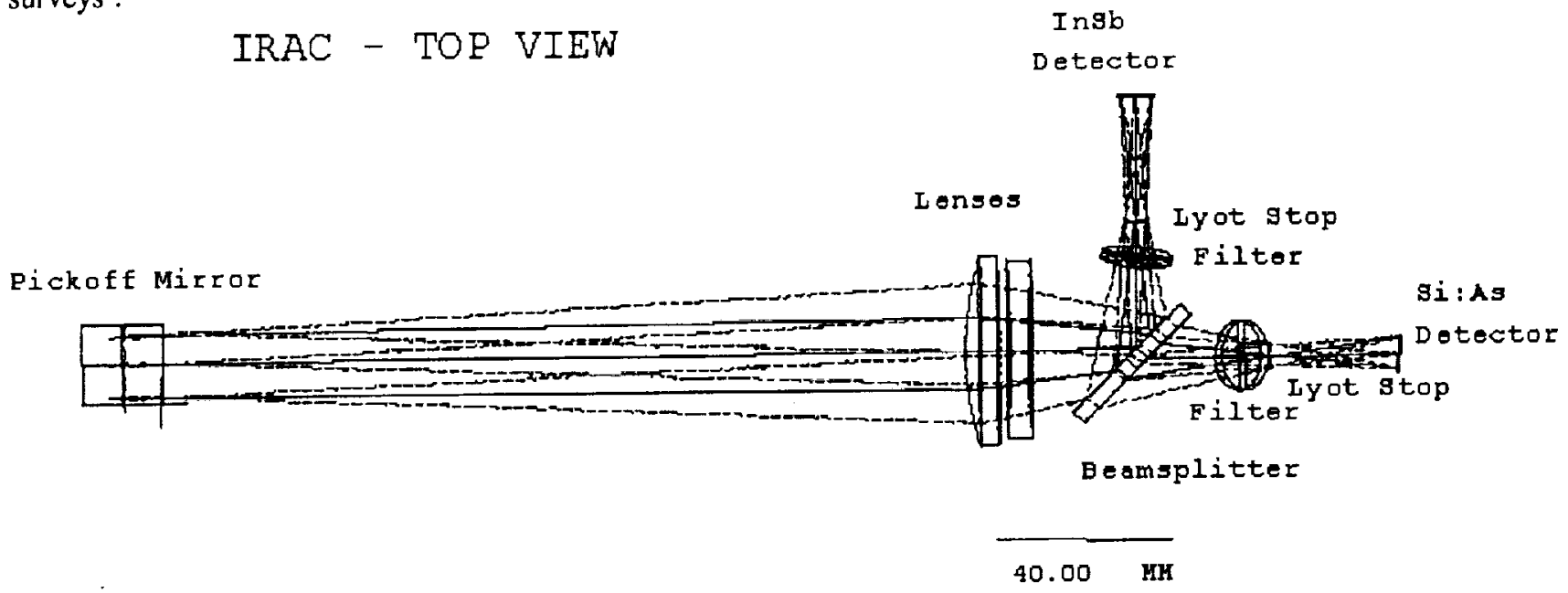

Figure 1. IRAC optical layout for each of the two fields of view. Each field of view has one dichroic beamsplitter, two bandpass filters, and two $256 \times 256$ pixel array detectors.

\subsection{Specifications}

Table 1 shows the specifications for both beamsplitters. Beamsplitter 1 is designed to have high reflectance in Channel 1 and high transmittance in Channel 3. Likewise, Beamsplitter 2 should have high reflectance in Channel 2 and high transmittance in Channel 4. Germanium was used as the substrate for both beamsplitters.

Table 1. Beamsplitter Specifications

\begin{tabular}{|c|c|c|}
\hline & Beamsplitter 1 & Beamsplitter 2 \\
\hline $\begin{array}{c}\text { Dimensions (mm): } \\
\text { Diameter: } \\
\text { Thickness: } \\
\text { Bevel: }\end{array}$ & $\begin{array}{c}39.00 \pm 0.05 \\
3.90 \pm 0.05 \\
0.25 \pm 0.05\end{array}$ & $\begin{array}{l}39.00 \pm 0.05 \\
3.90 \pm 0.05 \\
0.25 \pm 0.05\end{array}$ \\
\hline Usable clear aperture $(\mathrm{mm})$ : & 33.0 & 33.0 \\
\hline Angle of incidence: & $45^{\circ}$ & $45^{\circ}$ \\
\hline $\begin{array}{l}\text { Reflectance (front surface) } \\
\text { Average: }\end{array}$ & $\begin{array}{c}>90 \% \\
3.26 \mu \mathrm{m}-4.0 \mu \mathrm{m}\end{array}$ & $\begin{array}{c}>90 \% \\
4.0 \mu \mathrm{m}-5.06 \mu \mathrm{m}\end{array}$ \\
\hline Minimum: & $0.7 \times$ ave. reflectance & $0.7 \times$ ave. reflectance \\
\hline $\begin{array}{l}\text { Transmittance } \\
\text { Average: }\end{array}$ & $\begin{array}{l}>70 \%(\text { goal : }>85 \%) \\
5.06 \mu \mathrm{m}-6.5 \mu \mathrm{m}\end{array}$ & $\begin{array}{c}>70 \%(\text { goal: }>85 \%) \\
6.5 \mu \mathrm{m}-9.5 \mu \mathrm{m}\end{array}$ \\
\hline Minimum: & $0.8 \times$ ave. transmittance & $0.8 \times$ ave transmittance \\
\hline
\end{tabular}

Germanium substrates were also specified for the four bandpass filters. The $0.67-\mathrm{eV}$ bandgap of Ge provides short wavelength blocking below $1.8 \mu \mathrm{m}$. ${ }^{3}$ The desired filter characteristics are shown in Table 2 . In addition to these requirements, the polarization was specified to be $<5 \%$ difference between the transmitted $s$ component $\left(\mathrm{T}_{s}\right.$ ) and the transmitted $p$ component $\left(T_{p}\right)$ averaged between the $10^{-4}$ points on either side of the bandpass. 
Table 2. Filter Specifications

Channel 1 Filter Channel 2 Filter $\quad$ Channel 3 Filter $\quad$ Channel 4 Filter

\begin{tabular}{|c|c|c|c|c|}
\hline $\begin{array}{l}\text { Dimensions: } \\
\text { Diameter }(\mathrm{mm}): \\
\text { Thickness }(\mathrm{mm}):\end{array}$ & $\begin{array}{l}19.00 \pm 0.05 \\
3.00 \pm 0.05\end{array}$ & $\begin{array}{l}19.00 \pm 0.05 \\
3.00 \pm 0.05\end{array}$ & $\begin{array}{l}19.00 \pm 0.05 \\
3.90 \pm 0.05\end{array}$ & $\begin{array}{l}19.00 \pm 0.05 \\
3.90 \pm 0.05\end{array}$ \\
\hline Usable clear aperture (mm): & 12.5 & 12.0 & 17.0 & 14.0 \\
\hline Angle of incidence: & $11^{\circ}$ & $11^{\circ}$ & $45^{\circ}$ & $45^{\circ}$ \\
\hline Center Wavelength $(\mu \mathrm{m}) \pm 3 \%$ & 3.6 & 4.5 & 5.8 & 8.0 \\
\hline $\begin{array}{l}\text { Spectral Bandwidth }(\%) \pm 2 \% \text { of } \\
\text { center wavelength } \\
\text { Half-power points: }\end{array}$ & $\begin{array}{c}20.4 \\
3.2 \mu \mathrm{m}-4.00 \mu \mathrm{m}\end{array}$ & $\begin{array}{c}23.3 \\
4.00 \mu \mathrm{m}-5.06 \mu \mathrm{m}\end{array}$ & $\begin{array}{c}24.9 \\
5.06 \mu \mathrm{m}-6.50 \mu \mathrm{m}\end{array}$ & $\begin{array}{c}37.5 \\
6.50 \mu \mathrm{m}-9.50 \mu \mathrm{m}\end{array}$ \\
\hline $\begin{array}{c}\text { Average In-Band Transmittance } \\
(\%)\end{array}$ & $\begin{array}{c}>85 \\
\text { goal: }>90\end{array}$ & $\begin{array}{c}>85 \\
\text { goal: }>90\end{array}$ & $\begin{array}{c}>85 \\
\text { goal: }>90\end{array}$ & $\begin{array}{c}>85 \\
\text { goal: }>90\end{array}$ \\
\hline $\begin{array}{l}\text { Minimum In-Channel Optical } \\
\text { Efficiency (for } \pm 11.2 \% \text { of center } \\
\text { wavelength) }\end{array}$ & $\begin{array}{c}0.8 \times \text { ave. } \mathrm{T} \\
3.30 \mu \mathrm{m}-3.96 \mu \mathrm{m}\end{array}$ & $\begin{array}{c}0.8 \times \text { ave. T } \\
4.06 \mu \mathrm{m}-5.00 \mu \mathrm{m}\end{array}$ & $\begin{array}{c}0.8 \times \text { ave. } \mathrm{T} \\
5.13 \mu \mathrm{m}-6.43 \mu \mathrm{m}\end{array}$ & $\begin{array}{c}0.8 \times \text { ave. } \mathrm{T} \\
6.65 \mu \mathrm{m}-9.35 \mu \mathrm{m}\end{array}$ \\
\hline
\end{tabular}

\section{EXPERIMENTAL METHODS}

\subsection{Fourier Transform (FTIR) Spectrometer}

A Bruker IFSI13V Fourier transform spectrometer was used for the reflectance and transmittance measurements of these IRAC components. This instrument is a Genzel interferometer with a maximum resolution of $0.03 \mathrm{~cm}^{-1}$. It operates in vacuum to eliminate atmospheric absorption and noise caused by air currents. A Ge/KBr beamsplitter was used for the 2 to $25 \mu \mathrm{m}$ wavelength range, and a $3 \mu \mathrm{m}$ thick mylar beamspliter was used from 15 to $30 \mu \mathrm{m}$. The measurements reported here were done at $4 \mathrm{~cm}^{-1}$ resolution using a globar source and two DTGS detectors optimized for each spectral region.

Because all of these IRAC components operate and were tested at non-normal incidence, polarizers were required to separate the $s$ and $p$ components of the incident radiation. The polarizers, commercially available from Cambridge Physical Sciences, Ltd, consisted of $0.4 \mu \mathrm{m} \mathrm{Al}$ grids deposited on KRS-5 (ThBrI) substrates. With two of them in the beam, the transmittance of the unwanted polarization component was less than $0.8 \%$ between $2 \mu \mathrm{m}$ and $30 \mu \mathrm{m}$.

The IR beam in the spectrometer sample chamber was incident on the samples at $f / 3.5$. The reflectance measurements were referenced to an evaporated Au mirror and the results were corrected for the Au reflectance.

\subsection{Optical Cryostat}

Because the filters and beamsplitters had to be tested near the IRAC operating temperature of $1.4 \mathrm{~K}$, the samples were cooled in an Oxford Instruments Optistat CF continuous flow liquid helium cryostat. The cryostat was mounted on the vacuum box of the FTIR spectrometer with the optical tail extending into the sample chamber. During the cold measurements the samples were surrounded by $\mathrm{He}$ vapor at $\mathrm{T}=5 \mathrm{~K}$. This was warm enough to prevent the cryostat sample chamber from being flooded with boiling liquid helium, which made accurate optical measurements impossible, but cold enough to give results identical to $\mathrm{T}=1.4 \mathrm{~K}$. 
This arrangement required the IR beam to pass through four windows on the cryostat, two at room temperature and two at the same temperature as the sample. The cold windows separated the vacuum jacket of the cryostat from the 1 atm He gas in the sample chamber. The warm windows were needed because, at approximately $10 \mathrm{mbar}$, the pressure in the spectrometer vacuum box was several orders of magnitude too high to insulate the cryostat. $\mathrm{ZnSe}$ windows were used for the short wavelength range $(2 \mu \mathrm{m}$ to $20 \mu \mathrm{m})$ and polyethylene windows were used for the long wavelength range (15 $\mu \mathrm{m}$ to $30 \mu \mathrm{m})$.

\section{RESULTS}

\subsection{Beamsplitters}

The beamsplitters were manufactured by Barr Associates on high-purity Ge substrates. Beamsplitter 1 separates Channels 1 and 3. Beamsplitter 2 separates Channels 2 and 4 . Both operate as low-pass filters at an angle of incidence of $45^{\circ}$, reflecting the incident beam to the short wavelength filter (Channel 1 or 2), and transmitting the incident beam to the long wavelength filter (Channel 3 or 4 ).

Figure 2 shows both polarization components of the reflectance of Beamsplitter 1 at $5 \mathrm{~K}$ and room temperature. The corresponding transmittances are shown in Figure 3. The band edge between the highly reflecting and highly transmitting regions occurs at approximately $4.5 \mu \mathrm{m}$ and moves $0.11 \mu \mathrm{m}$ shorter in wavelength as the temperature decreases from $296 \mathrm{~K}$ to $5 \mathrm{~K}$. The band edge for the $p$ component occurs at $0.09 \mu \mathrm{m}$ shorter wavelength than the $s$ component at both temperatures.

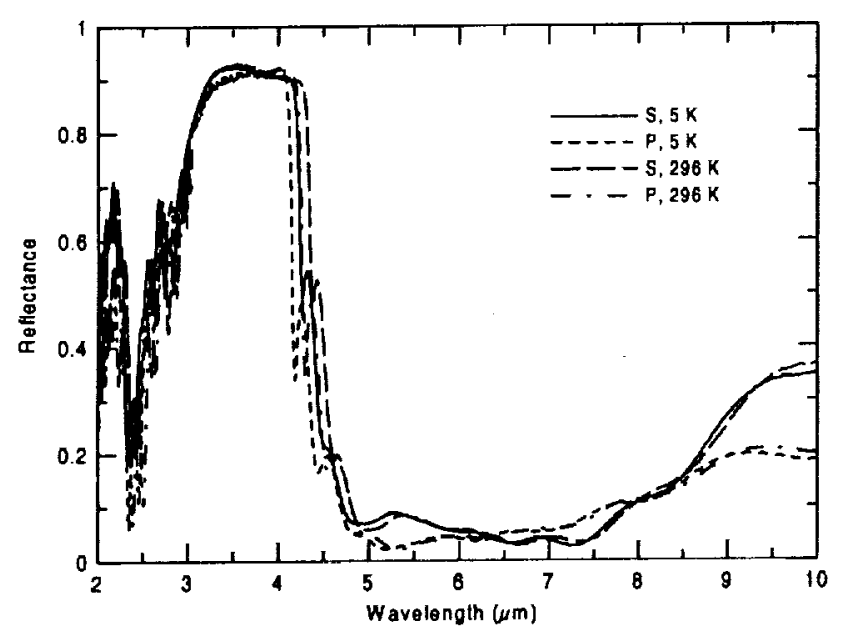

Figure 2. The reflectance of Beamsplitter 1 measured at an angle of incidence of $45^{\circ}$.

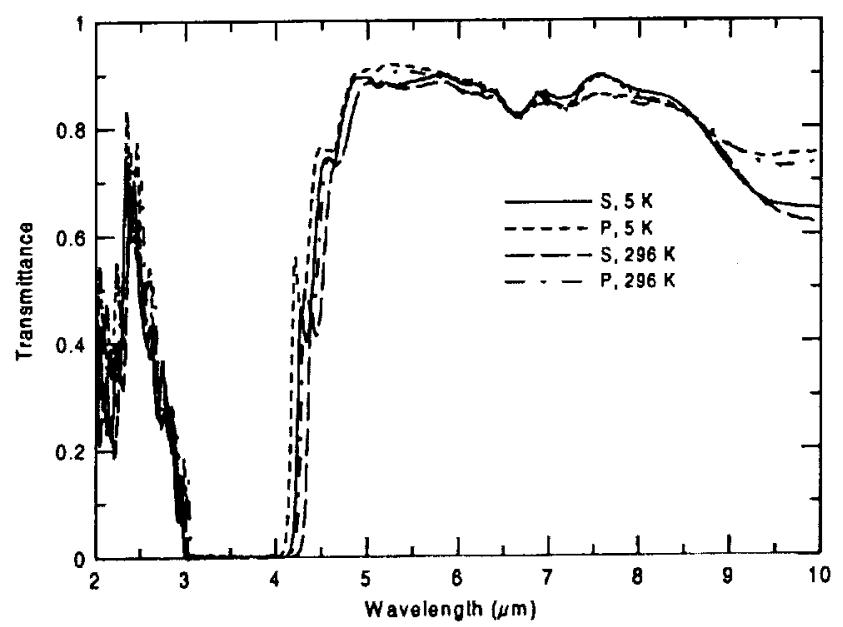

Figure 3. The transmittance of Beamsplitter 1 measured at an angle of incidence of $45^{\circ}$.

Beamsplitter 2 is very similar to number 1 , but its low-pass edge occurs $1 \mu \mathrm{m}$ longer in wavelength, at approximately $5.5 \mu \mathrm{m}$. The reflectance and transmittance of Beamsplitter 2 are shown in Figure 4 and Figure 5. Its low-pass cutoff moves $0.13 \mu \mathrm{m}$ shorter in wavelength as the temperature decreases from $296 \mathrm{~K}$ to $5 \mathrm{~K}$, and the $p$ component cutoff occurs $0.11 \mu \mathrm{m}$ shorter than the $s$ component at both temperatures.

\subsection{Bandpass Filters}

The four bandpass filters were manufactured by Optical Coating Laboratories, Inc. on high-purity Ge substrates. Figure 6 and Figure 7 show the transmittance of Filters 1 and 2, respectively. At $11^{\circ}$ angle of incidence, the $s$ and $p$ components are nearly identical so the $p$ component measurements are not shown in these figures. For Filter 1 , the short wavelength half power point, $\lambda_{1}$, decreases by $0.08 \mu \mathrm{m}$ as the temperature decreases from room temperature to $5 \mathrm{~K}$. The long wavelength half power point, $\lambda_{2}$, decreases only half as much, $0.04 \mu \mathrm{m}$, between these two temperatures. For Filter $2, \lambda_{1}$ shifts $0.10 \mu \mathrm{m}$ shorter. Again, $\lambda_{2}$ changes half as much, $0.05 \mu \mathrm{m}$, between $296 \mathrm{~K}$ and $5 \mathrm{~K}$. 


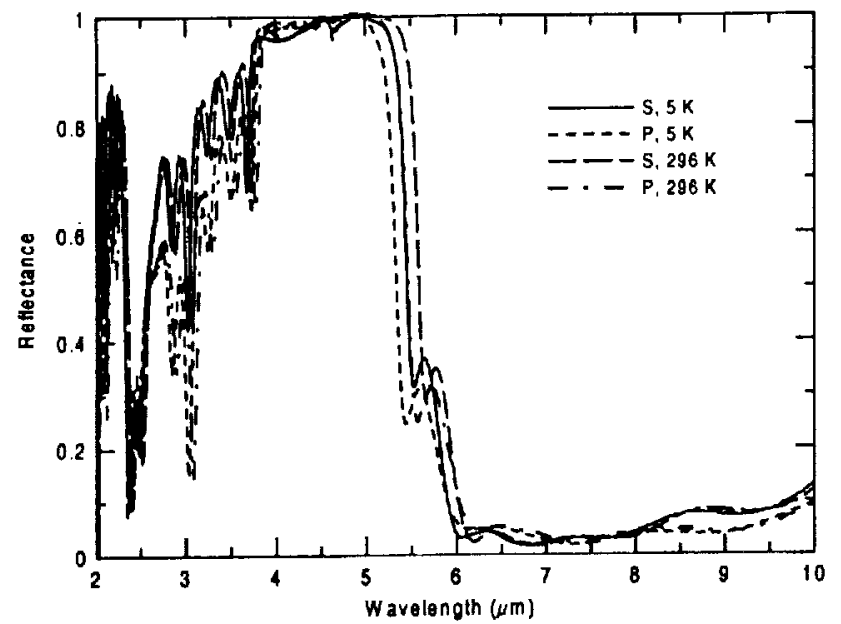

Figure 4. Reflectance of Beamsplitter 2 measured at an angle of incidence of $45^{\circ}$.

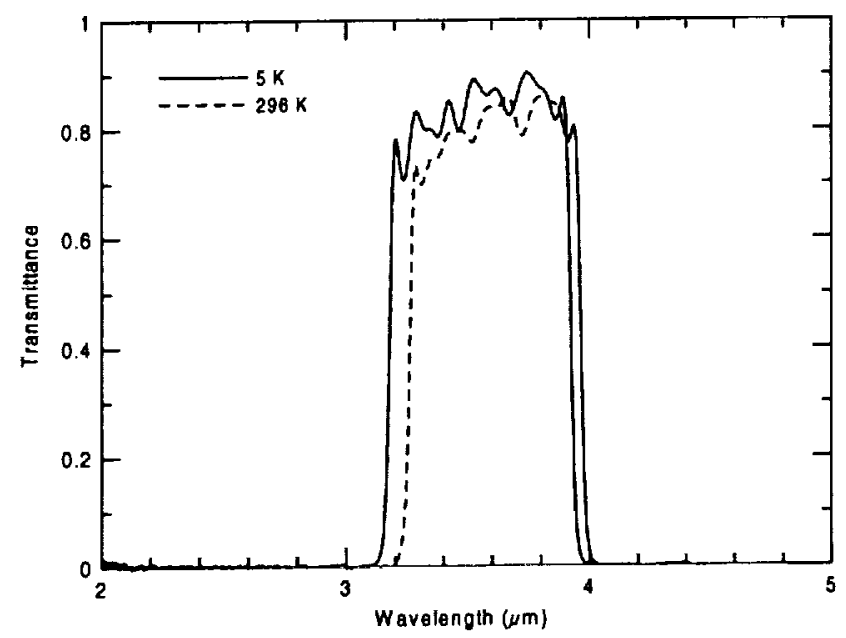

Figure 6. Filter 1 measured at an angle of incidence of $11^{\circ}$.

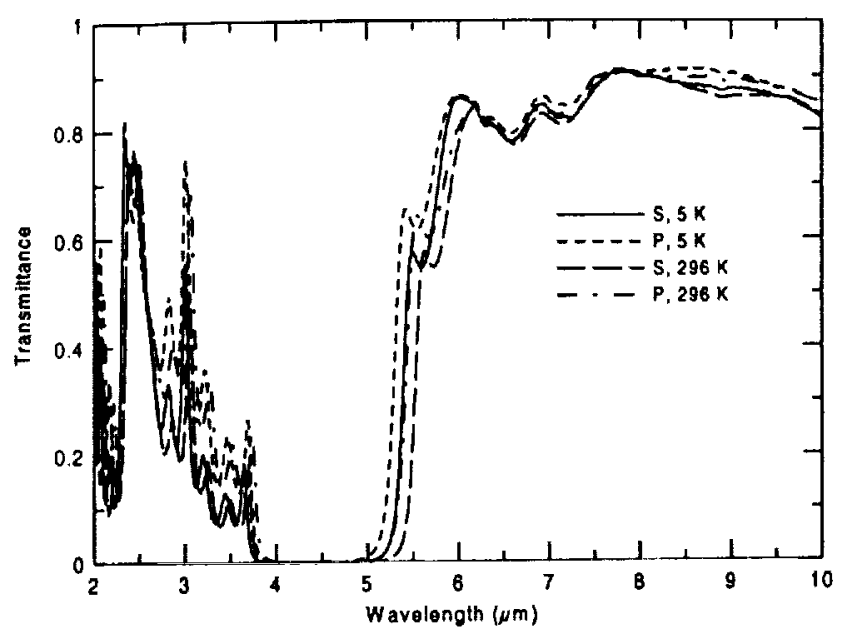

Figure 5. Transmittance of Beamsplitter 2 measured at an angle of incidence of $45^{\circ}$.

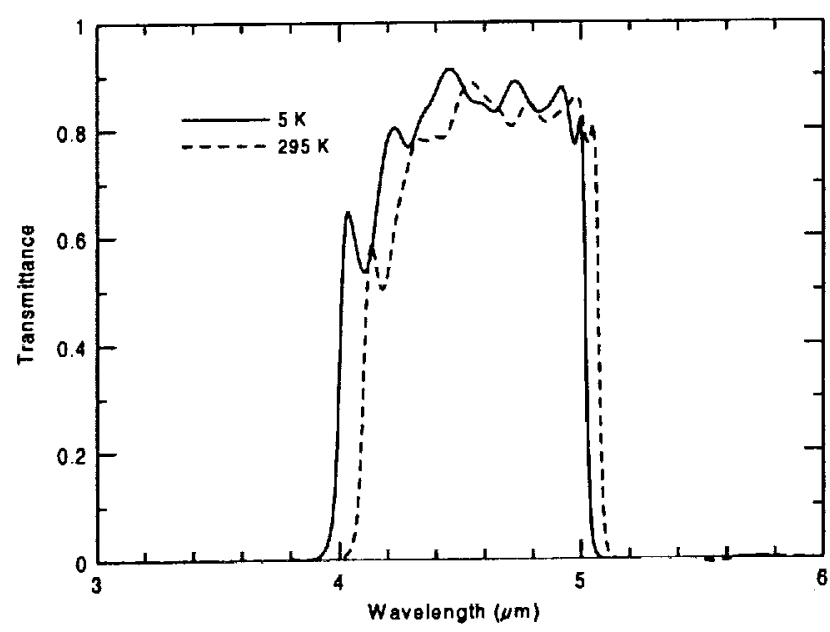

Figure 7. Filter 2 measured at an angle of incidence of $11^{\circ}$.

The transmittance of Filters 3 and 4 at $45^{\circ}$ angle of incidence are shown in Figure 8 and Figure 9. The changes with temperature do not follow the same pattern as the previous two filters, but in all cases the bandpass edge of the $p$ component moves in the same direction, and by the same amount, as the $s$ component. As the temperature of Filter 3 changes from $296 \mathrm{~K}$ to $5 \mathrm{~K}, \lambda_{1}$ decreases by $0.07 \mu \mathrm{m}$ and $\lambda_{2}$ decreases by $0.10 \mu \mathrm{m}$. The corresponding values for Filter are $0.12 \mu \mathrm{m}$ and $0.10 \mu \mathrm{m}$. For all of the filters except number 3 , the pass band shifts to shorter wavelength and becomes approximately $1 \%$ wider at liquid helium temperature. The center wavelength of Filter 3 also decreases, but, unlike the other filters, the pass band narrows very slightly. The filter results are summarized in Table 3 for $296 \mathrm{~K}$, and Table 4 for $5 \mathrm{~K}$. 
Table 3. IRAC Filter measurements, $T=296 \mathrm{~K}$.

\begin{tabular}{|c|c|c|c|c|}
\hline & Channel 1 & Channel 2 & Channel 3 & Channel 4 \\
\hline$\lambda_{1}\left(50 \%\right.$ of $\left.T_{a v e}\right)$ & $\begin{array}{l}3.262 \mu \mathrm{m}(\mathrm{S}) \\
3.258 \mu \mathrm{m}(\mathrm{P})\end{array}$ & $\begin{array}{l}4.105 \mu \mathrm{m}(\mathrm{S}) \\
4.099 \mu \mathrm{m}(\mathrm{P})\end{array}$ & $\begin{array}{l}5.090 \mu \mathrm{m}(\mathrm{S}) \\
5.049 \mu \mathrm{m}(\mathrm{P})\end{array}$ & $\begin{array}{l}6.572 \mu \mathrm{m}(\mathrm{S}) \\
6.526 \mu \mathrm{m}(\mathrm{P})\end{array}$ \\
\hline$\lambda_{2}\left(50 \%\right.$ of $\left.\mathrm{T}_{\mathrm{ave}}\right)$ & $\begin{array}{l}3.967 \mu \mathrm{m}(\mathrm{S}) \\
3.969 \mu \mathrm{m}(\mathrm{P})\end{array}$ & $\begin{array}{l}5.075 \mu \mathrm{m}(\mathrm{S}) \\
5.079 \mu \mathrm{m}(\mathrm{P})\end{array}$ & $\begin{array}{l}6.502 \mu \mathrm{m}(\mathrm{S}) \\
6.562 \mu \mathrm{m}(\mathrm{P})\end{array}$ & $\begin{array}{l}9.373 \mu \mathrm{m}(\mathrm{S}) \\
9.521 \mu \mathrm{m}(\mathrm{P})\end{array}$ \\
\hline $\begin{array}{c}\text { Center Wavelength } \\
{\left[\lambda_{1}+\lambda_{2}\right] / 2}\end{array}$ & $\begin{array}{l}3.614 \mu \mathrm{m}(\mathrm{S}) \\
3.614 \mu \mathrm{m}(\mathrm{P})\end{array}$ & $\begin{array}{l}4.590 \mu \mathrm{m}(\mathrm{S}) \\
4.589 \mu \mathrm{m}(\mathrm{P})\end{array}$ & $\begin{array}{l}5.796 \mu \mathrm{m}(\mathrm{S}) \\
5.805 \mu \mathrm{m}(\mathrm{P})\end{array}$ & $\begin{array}{l}7.973 \mu \mathrm{m}(\mathrm{S}) \\
8.024 \mu \mathrm{m}(\mathrm{P})\end{array}$ \\
\hline $\begin{array}{l}\text { Average in-band Transmittance } \\
\qquad T_{\text {ave }}=\int T(\lambda) d \lambda\left[\lambda_{2}-\lambda_{1}\right]\end{array}$ & $\begin{array}{l}79.2 \%(\mathrm{~S}) \\
78.5 \%(\mathrm{P})\end{array}$ & $\begin{array}{l}77.6 \%(\mathrm{~S}) \\
78.0 \%(\mathrm{P})\end{array}$ & $\begin{array}{l}60.0 \%(\mathrm{~S}) \\
65.7 \%(\mathrm{P})\end{array}$ & $\begin{array}{l}55.8 \%(\mathrm{~S}) \\
61.5 \%(\mathrm{P})\end{array}$ \\
\hline $\begin{array}{c}\text { In-band Polarization } \\
{\left[\mathrm{T}_{\text {ave }}(\mathrm{S})-\mathrm{T}_{\text {ave }}(\mathrm{P})\right] /\left[\mathrm{T}_{\text {ave }}(\mathrm{S})+\mathrm{T}_{\text {ave }}(\mathrm{P})\right]}\end{array}$ & $0.466 \%$ & $0.231 \%$ & $4.48 \%$ & $4.82 \%$ \\
\hline Minimum in-band Transmittance & $\begin{array}{l}70.0 \%(\mathrm{~S}) \\
70.0 \%(\mathrm{P})\end{array}$ & $\begin{array}{l}50.0 \%(\mathrm{~S}) \\
50.0 \%(\mathrm{P})\end{array}$ & $\begin{array}{l}53.0 \%(\mathrm{~S}) \\
60.1 \%(\mathrm{P})\end{array}$ & $\begin{array}{l}40.0 \%(\mathrm{~S}) \\
55.0 \%(\mathrm{P})\end{array}$ \\
\hline
\end{tabular}

Table 4. IRAC filter measurements, $\mathrm{T}=5 \mathrm{~K}$.

\begin{tabular}{|c|c|c|c|c|}
\hline & Channel I & Channel 2 & Channel 3 & Channel 4 \\
\hline$\lambda_{1}\left(50 \%\right.$ of $\left.T_{\text {ave }}\right)$ & $\begin{array}{l}3.178 \mu \mathrm{m}(\mathrm{S}) \\
3.176 \mu \mathrm{m}(\mathrm{P})\end{array}$ & $\begin{array}{l}4.004 \mu \mathrm{m}(\mathrm{S}) \\
4.000 \mu \mathrm{m}(\mathrm{P})\end{array}$ & $\begin{array}{l}5.019 \mu \mathrm{m}(\mathrm{S}) \\
4.973 \mu \mathrm{m}(\mathrm{P})\end{array}$ & $\begin{array}{l}6.447 \mu \mathrm{m}(\mathrm{S}) \\
6.404 \mu \mathrm{m}(\mathrm{P})\end{array}$ \\
\hline$\lambda_{2}\left(50 \%\right.$ of $\left.\mathrm{T}_{\text {ave }}\right)$ & $\begin{array}{l}3.926 \mu \mathrm{m}(\mathrm{S}) \\
3.928 \mu \mathrm{m}(\mathrm{P})\end{array}$ & $\begin{array}{l}5.021 \mu \mathrm{m}(\mathrm{S}) \\
5.026 \mu \mathrm{m}(\mathrm{P})\end{array}$ & $\begin{array}{l}6.401 \mu \mathrm{m}(\mathrm{S}) \\
6.458 \mu \mathrm{m}(\mathrm{P})\end{array}$ & $\begin{array}{l}9.271 \mu \mathrm{m}(\mathrm{S}) \\
9.420 \mu \mathrm{m}(\mathrm{P})\end{array}$ \\
\hline $\begin{array}{c}\text { Center Wavelength } \\
{\left[\lambda_{1}+\lambda_{2}\right] / 2}\end{array}$ & $\begin{array}{l}3.552 \mu \mathrm{m}(\mathrm{S}) \\
3.552 \mu \mathrm{m}(\mathrm{P})\end{array}$ & $\begin{array}{l}4.513 \mu \mathrm{m}(\mathrm{S}) \\
4.513 \mu \mathrm{m}(\mathrm{P})\end{array}$ & $\begin{array}{l}5.710 \mu \mathrm{m}(\mathrm{S}) \\
5.716 \mu \mathrm{m}(\mathrm{P})\end{array}$ & $\begin{array}{l}7.859 \mu \mathrm{m}(\mathrm{S}) \\
7.912 \mu \mathrm{m}(\mathrm{P})\end{array}$ \\
\hline $\begin{array}{l}\text { Average in-band Transmittance } \\
T_{\text {ave }}=\int \mathrm{T}(\lambda) \mathrm{d} \lambda\left[\lambda_{2}-\lambda_{1}\right]\end{array}$ & $\begin{array}{l}82.4 \%(S) \\
82.4 \%(\mathrm{P})\end{array}$ & $\begin{array}{l}79.7 \%(\mathrm{~S}) \\
80.5 \%(\mathrm{P})\end{array}$ & $\begin{array}{l}66.2 \%(\mathrm{~S}) \\
72.8 \%(\mathrm{P})\end{array}$ & $\begin{array}{l}63.4 \%(\mathrm{~S}) \\
68.5 \%(\mathrm{P})\end{array}$ \\
\hline $\begin{array}{c}\text { In-band Polarization } \\
{\left[\mathrm{T}_{\text {ave }}(\mathrm{S})-\mathrm{T}_{\text {ave }}(\mathrm{P})\right] /\left[\mathrm{T}_{\text {ave }}(\mathrm{S})+\mathrm{T}_{\text {ave }}(\mathrm{P})\right]}\end{array}$ & $0.001 \%$ & $0.532 \%$ & $4.70 \%$ & $3.859 \%$ \\
\hline Minimum in-band Transmittance & $\begin{array}{l}70.0 \%(\mathrm{~S}) \\
70.0 \%(\mathrm{P})\end{array}$ & $\begin{array}{l}52.0 \%(\mathrm{~S}) \\
52.5 \%(\mathrm{P})\end{array}$ & $\begin{array}{l}59.0 \%(\mathrm{~S}) \\
70.0 \%(\mathrm{P})\end{array}$ & $\begin{array}{l}58.0 \%(\mathrm{~S}) \\
63.0 \%(\mathrm{P})\end{array}$ \\
\hline
\end{tabular}




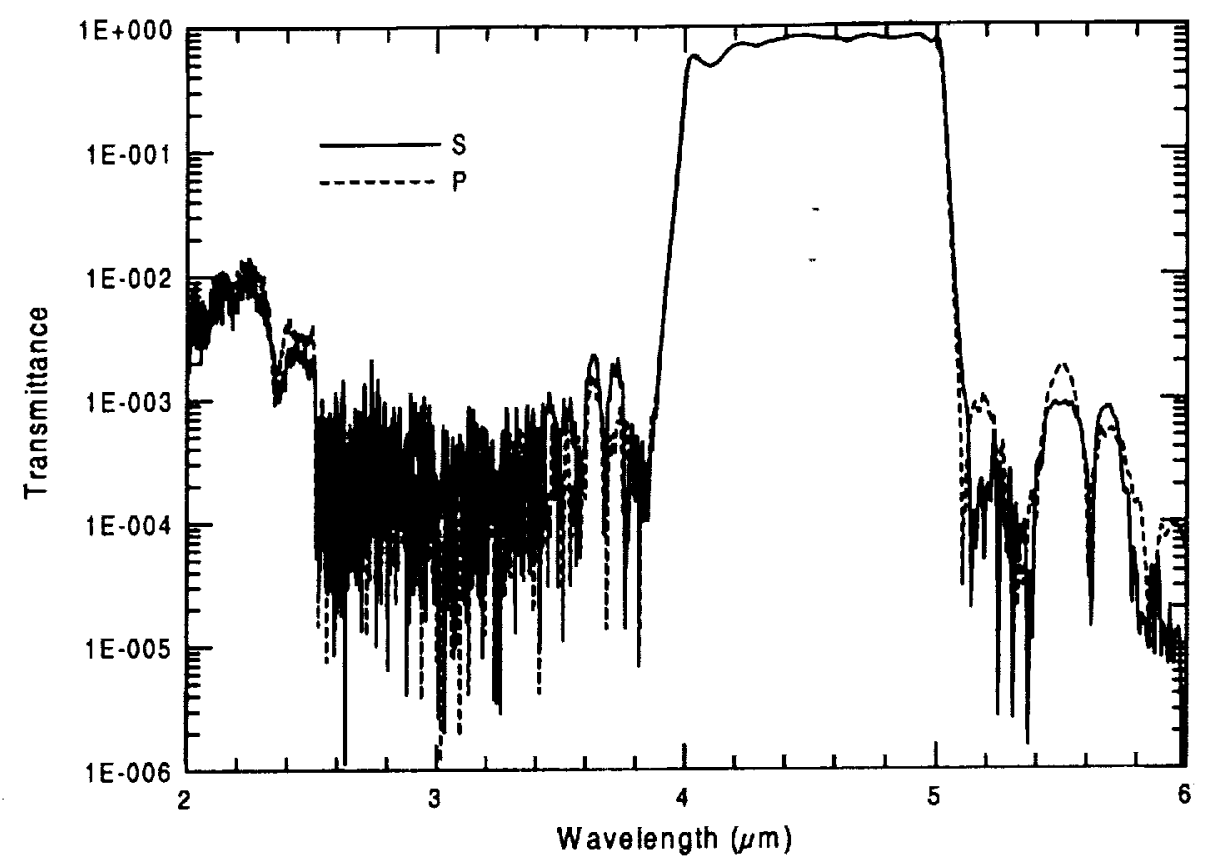

Figure 11. Channel 2 performance.

Channels 3 and 4 have more stringent out-of-band blocking requirements because the sensitivity of the Si:As detector arrays extends out to nearly $30 \mu \mathrm{m}$. The out-of-band transmittance requirement of $<10^{-6}$ to $16 \mu \mathrm{m}$ and $<10^{-8}$ for $16 \mu \mathrm{m}<\lambda<30 \mu \mathrm{m}$ prevents sources which are too cold to radiate much energy in the Channel 3 and 4 bandpass regions from erroneously affecting the astronomical measurements. Channel 3 has a leak at the $10^{-4}$ level around $18 \mu \mathrm{m}$. Channel 4 meets the requirement beyond $22 \mu \mathrm{m}$, but transmits as much as $10^{5}$ near $20 \mu \mathrm{m}$, and $10^{3}$ below $18 \mu \mathrm{m}$.

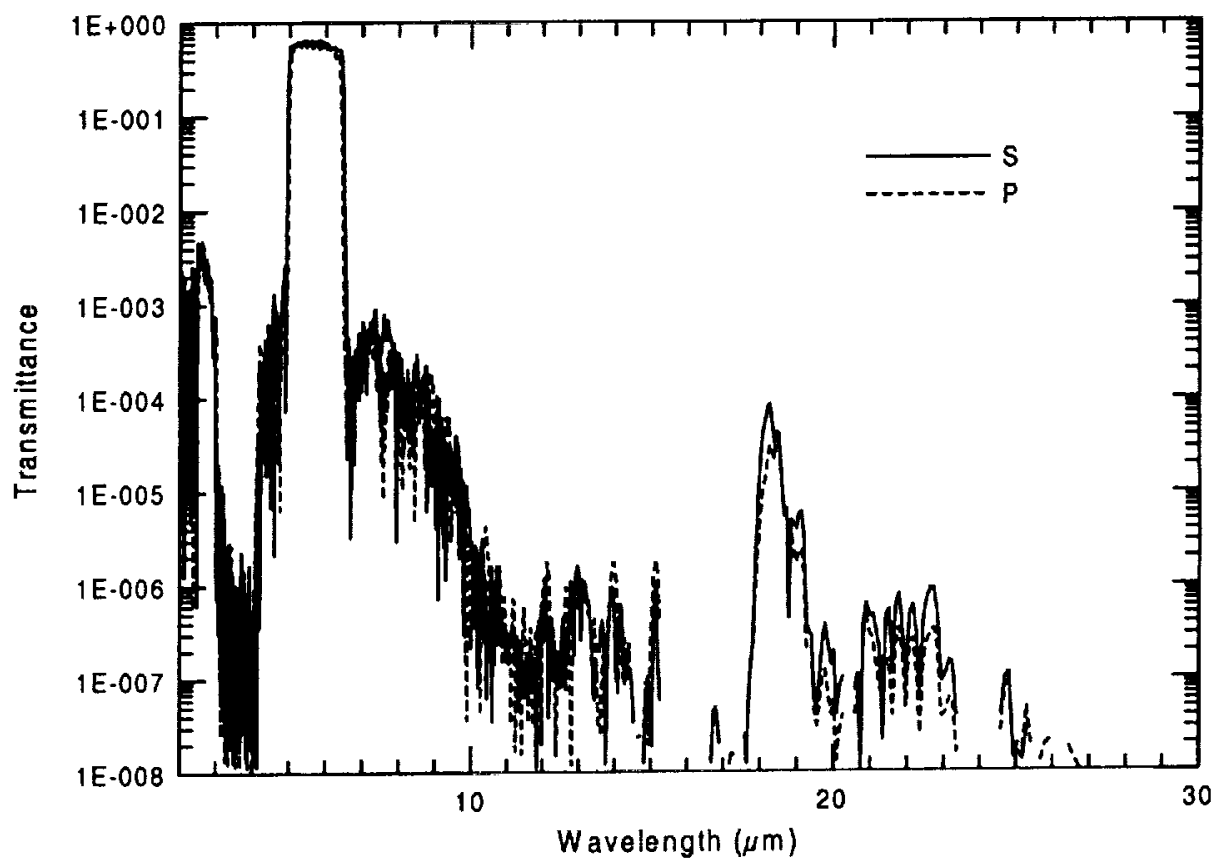

Figure 12. Channel 3 performance. 


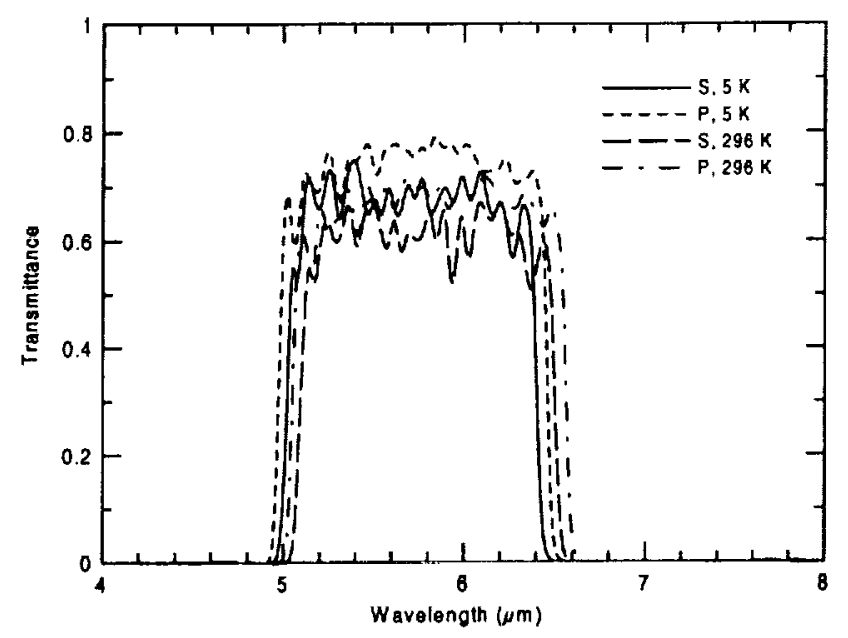

Figure 8. Filter 3 measured at an angle of incidence of $45^{\circ}$.

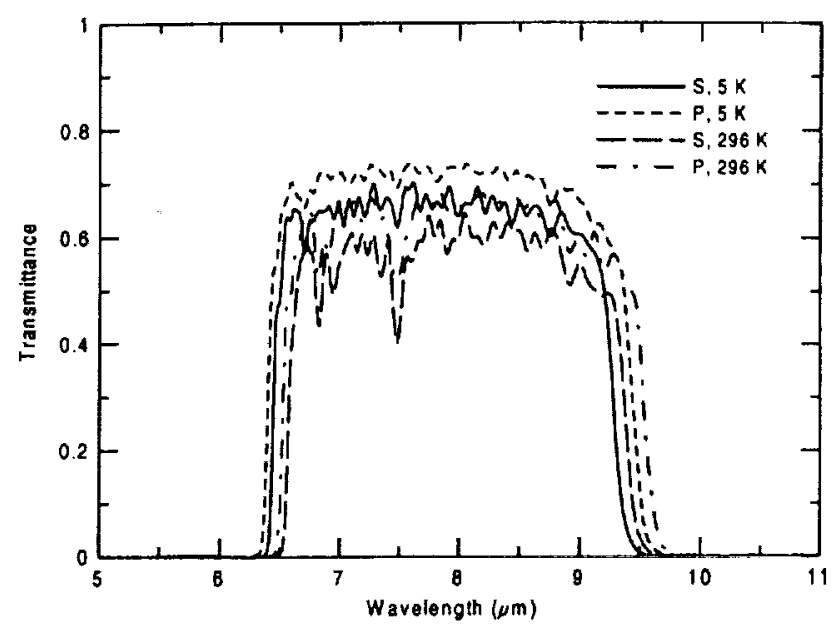

Figure 9. Filter 4 measured at an angle of incidence of $45^{\circ}$.

\subsection{Combined Beamsplitter and Filter Performance}

Figure 10 through Figure 13 are the total performance of the IRAC optical system between the pickoff mirror and the detector arrays plotted on a log scale to show the out-of-band blocking. This includes the transmittance of the lenses, the transmittance (or reflectance, as appropriate) of the beamsplitters, and the transmittance of the filters. The $s$ and $p$ labels for these curves indicate the polarization components with respect to the beamsplitters, which, due to the IRAC optical geometry, is the opposite of the polarization relative to the plane of incidence of the filters. Figure 10 and Figure 11 show the total efficiency for Channels 1 and 2 from $2 \mu \mathrm{m}$ to the InSb detector cutoff at $6 \mu \mathrm{m}$. Due to the decreasing source intensity and FTIR beamsplitter efficiency near $2 \mu \mathrm{m}$, the out-of-band data at the short wavelength end of all four channels are noise limited. The curves show the instrument noise level rather than actual transmitted energy. The real blocking may be greater than indicated. The other features in all four graphs are above the measurement noise level.

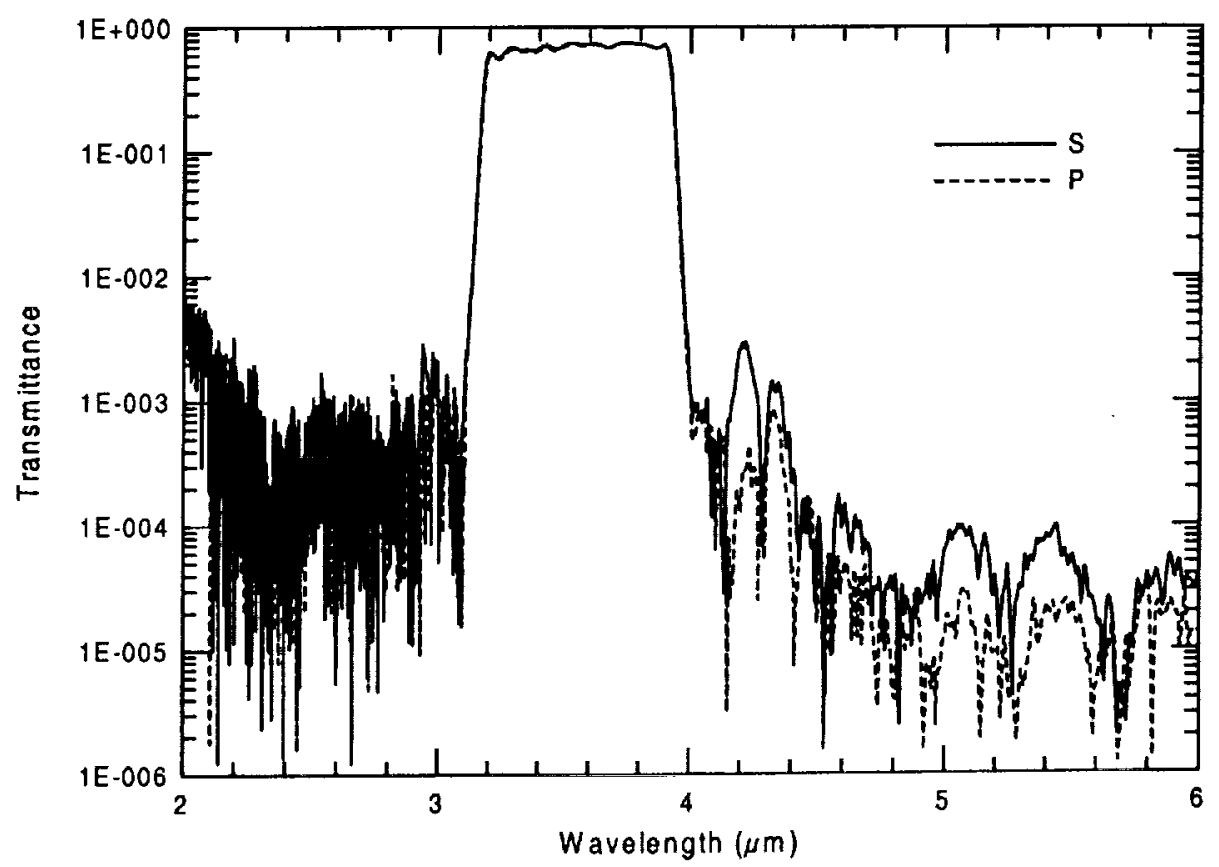

Figure 10. Channel 1 performance. 


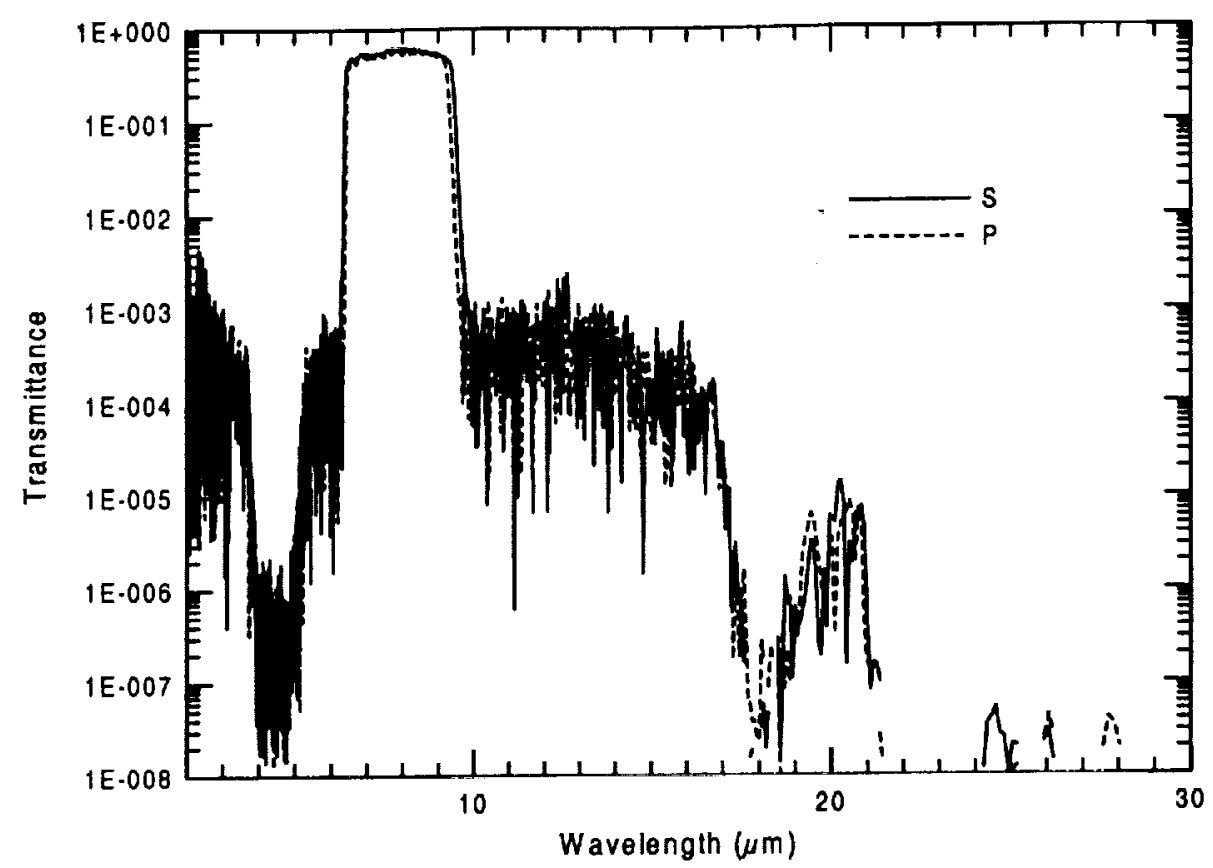

Figure 13. Channel 4 performance.

Table 5. IRAC Optical Efficiency, $T=5 \mathrm{~K}$.

\begin{tabular}{|c|c|c|c|c|}
\hline & Channel 1 & Channel 2 & Channel 3 & Channel 4 \\
\hline$\lambda_{1}\left(50 \%\right.$ of $\left.\mathrm{T}_{\mathrm{ave}}\right)$ & $\begin{array}{l}3.176 \mu \mathrm{m}(\mathrm{S}) \\
3.180 \mu \mathrm{m}(\mathrm{P})\end{array}$ & $\begin{array}{l}4.001 \mu \mathrm{m}(\mathrm{S}) \\
4.005 \mu \mathrm{m}(\mathrm{P})\end{array}$ & $\begin{array}{l}5.020 \mu \mathrm{m}(\mathrm{S}) \\
5.018 \mu \mathrm{m}(\mathrm{P})\end{array}$ & $\begin{array}{l}6.407 \mu \mathrm{m}(\mathrm{S}) \\
6.450 \mu \mathrm{m}(\mathrm{P})\end{array}$ \\
\hline$\lambda_{2}\left(50 \%\right.$ of $\left.T_{\text {ave }}\right)$ & $\begin{array}{l}3.928 \mu \mathrm{m}(\mathrm{S}) \\
3.926 \mu \mathrm{m}(\mathrm{P})\end{array}$ & $\begin{array}{l}5.026 \mu \mathrm{m}(\mathrm{S}) \\
5.022 \mu \mathrm{m}(\mathrm{P})\end{array}$ & $\begin{array}{l}6.454 \mu \mathrm{m}(\mathrm{S}) \\
6.396 \mu \mathrm{m}(\mathrm{P})\end{array}$ & $\begin{array}{l}9.420 \mu \mathrm{m}(\mathrm{S}) \\
9.272 \mu \mathrm{m}(\mathrm{P})\end{array}$ \\
\hline $\begin{array}{c}\text { Center Wavelength } \\
{\left[\lambda_{1}+\lambda_{2}\right] / 2}\end{array}$ & $\begin{array}{l}3.552 \mu \mathrm{m}(\mathrm{S}) \\
3.553 \mu \mathrm{m}(\mathrm{P})\end{array}$ & $\begin{array}{l}4.514 \mu \mathrm{m}(\mathrm{S}) \\
4.514 \mu \mathrm{m}(\mathrm{P})\end{array}$ & $\begin{array}{l}5.737 \mu \mathrm{m}(\mathrm{S}) \\
5.707 \mu \mathrm{m}(\mathrm{P})\end{array}$ & $\begin{array}{l}7.914 \mu \mathrm{m}(\mathrm{S}) \\
7.861 \mu \mathrm{m}(\mathrm{P})\end{array}$ \\
\hline Spectral Bandwidth & $\begin{array}{l}21.2 \%(\mathrm{~S}) \\
21.0 \%(\mathrm{P})\end{array}$ & $\begin{array}{l}22.7 \%(\mathrm{~S}) \\
22.5 \%(\mathrm{P})\end{array}$ & $\begin{array}{l}25.0 \%(\mathrm{~S}) \\
24.2 \%(\mathrm{P})\end{array}$ & $\begin{array}{l}38.1 \%(\mathrm{~S}) \\
35.9 \%(\mathrm{P})\end{array}$ \\
\hline $\begin{array}{l}\text { Average in-band Transmittance } \\
\qquad T_{\text {ave }}=\int T(\lambda) \mathrm{d} \lambda /\left[\lambda_{2}-\lambda_{1}\right]\end{array}$ & $\begin{array}{l}68.8 \%(\mathrm{~S}) \\
67.7 \%(\mathrm{P})\end{array}$ & $\begin{array}{l}73.2 \%(\mathrm{~S}) \\
72.8 \%(\mathrm{P})\end{array}$ & $\begin{array}{l}58.6 \%(\mathrm{~S}) \\
54.2 \%(\mathrm{P})\end{array}$ & $\begin{array}{l}54.8 \%(\mathrm{~S}) \\
51.8 \%(\mathrm{P})\end{array}$ \\
\hline $\begin{array}{c}\text { In-band Polarization } \\
{\left[\mathrm{T}_{\text {ave }}(\mathrm{s})-\mathrm{T}_{\mathrm{ave}}(\mathrm{P})\right] /\left[\mathrm{T}_{\text {ave }}(\mathrm{s})+\mathrm{T}_{\text {ave }}(\mathrm{p})\right]}\end{array}$ & $0.794 \%$ & $0.282 \%$ & $3.87 \%$ & $2.79 \%$ \\
\hline Minimum in-band Transmittance & $\begin{array}{l}57.4 \%(\mathrm{~S}) \\
55.9 \%(\mathrm{P})\end{array}$ & $\begin{array}{l}48.4 \%(\mathrm{~S}) \\
48.2 \%(\mathrm{P})\end{array}$ & $\begin{array}{l}51.7 \%(\mathrm{~S}) \\
42.1 \%(\mathrm{P})\end{array}$ & $\begin{array}{l}47.6 \%(\mathrm{~S}) \\
42.4 \%(\mathrm{P})\end{array}$ \\
\hline
\end{tabular}


The measured bandpass data for the IRAC instrument are summarized in Table 5, which shows good agreement with the specifications in Table 2 . The average in-band transmittance falls short of the goal of $80 \%$ due mainly to the need to improve the long wavelength blocking.

\section{CONCLUSIONS}

These filters and beamsplitters represent the current state-of-the-art for multilayer thin film infrared components, providing good in-band transmittance, steep band edges, low polarization, and good out-of-band blocking. They are the best efforts of the vendors to meet the very rigorous IRAC specifications at cryogenic temperatures. There was a trade-off between in-band performance and out-of-band blocking. Despite the non-normal angle of incidence on all of the components, the instrument has less than $4 \%$ affect on the polarization of the incoming light. When cooled from room temperature, the center wavelength of each channel decreases by approximately $1.5 \%$, and the bandwidth increases by $1 \%$ or less.

\section{REFERENCES}

${ }^{1}$ G. G. Fazio, J. L. Hora, S. P. Wilner, J. R. Stauffer, M. L. N. Ashby, Z. Wang, E. V. Tollestrup, J. Pipher, W. Forrest, C. McCreight, S. H. Moseley, W. F. Hoffmann, P. Eisenhardt, and E. L. Wright, Infrared Astronomical Instrumentation, Proc. SPIE, 3356-1 (1998).

${ }^{2}$ M. D. Bicay, M. W. Werner, \& L. L. Simmons, Infrared Astronomical Instrumentation, Proc. SPIE, 3356- 109 (1998).

${ }^{3}$ Paul Klocek, ed., Handbook of Infrared Optical Materials (Marcel Dekker, New York, 1991), p. 262.

${ }^{4}$ K. P. Stewart, Ph. D. dissertation, University of Maryland (1997). 